\title{
Vascular adaptation of the internal thoracic artery graft early and late after bypass surgery
}

\author{
Beat H. Walpoth, MD, ${ }^{a}$ Markus Schmid, MD, ${ }^{\mathrm{b}}$ Anna Schwab, MD, ${ }^{\mathrm{b}}$ Andreas Bosshard, MD, ${ }^{\mathrm{b}}$ Friedrich Eckstein, MD, \\ Thierry Carrel, MD, and Otto M. Hess, MD ${ }^{\mathrm{b}}$
}

Objective: Flow mismatch between the supplying artery and the myocardial perfusion region has been observed in patients with internal thoracic artery grafts. Thus coronary flow changes of arterial (internal thoracic artery grafts) and saphenous (saphenous vein grafts) bypass grafts were studied early and late after coronary artery bypass grafting.

Methods: Thirty patients undergoing elective bypass surgery (internal thoracic artery and saphenous vein grafts) were studied intraoperatively and (17 patients) 3 to 10 months postoperatively. Coronary flow was measured intraoperatively with the transit-time Doppler scanning technique. Postoperatively, flow velocity and coronary flow reserve were determined with the Doppler flow wire technique. Quantitative angiographic analysis was used to determine vessel size for calculation of absolute flow.

From the Cardiovascular Surgery, ${ }^{\text {a }}$ University Hospital, Geneva, Switzerland, and the Swiss Cardiovascular Center, ${ }^{\mathrm{b}}$ University Hospital Bern, Bern, Switzerland.

The study was partly funded by the Swiss Heart Foundation and the University Hospital of Bern.

Received for publication Sept 26, 2007; revisions received April 18, 2008; accepted for publication May 19, 2008.

Address for reprints: Beat H. Walpoth, MD, Cardiovascular Research, Geneva University Hospital, 1211 Geneva 14, Switzerland (E-mail: beat.walpoth@hcuge.ch).

J Thorac Cardiovasc Surg 2008;136:876-83 $0022-5223 / \$ 34.00$

Copyright $\odot 2008$ by The American Association for Thoracic Surgery

doi:10.1016/j.jtcvs.2008.05.029
Results: Intraoperatively, internal thoracic artery graft flow was significantly lower than saphenous vein graft flow ( $31 \pm 8$ vs $58 \pm 29 \mathrm{~mL} / \mathrm{min}, P<.01)$. Postoperatively, internal thoracic artery graft flow increased significantly to $42 \pm 24 \mathrm{~mL} / \mathrm{min}$ at 3 months and to $56 \pm 30 \mathrm{~mL} / \mathrm{min}(P<.02$ vs intraoperative value) at 10 months, respectively. However, saphenous vein graft flow remained unchanged over time ( $58 \pm 29$ to $50 \pm 27 \mathrm{~mL} / \mathrm{min}$ at 3 months and $46 \pm 27 \mathrm{~mL} / \mathrm{min}$ at 10 months). Coronary flow reserve was abnormally low intraoperatively in the internal thoracic artery $(1.3 \pm 0.3)$ and saphenous vein $(1.6 \pm 0.5)$ grafts but increased significantly to normal values in both types of graft at follow-up.

Conclusions: Bypass flow of the internal thoracic artery graft is significantly reduced intraoperatively when compared with that of the saphenous vein graft. However, 3 and 10 months after the operation, flow of the internal thoracic artery graft increases significantly and is similar to saphenous vein graft flow. This finding can be explained by an early flow mismatch of the native internal thoracic artery in the presence of a large perfusion territory. During follow-up, there is vascular remodeling of the internal thoracic artery, probably because of endothelium-mediated mechanisms.

$\mathrm{C}$ oronary artery bypass grafting $(\mathrm{CABG})$ has been associated with excellent clinical results with regard to outcome and long-term follow-up. ${ }^{1}$ However, clinical results have been shown to be different for saphenous vein grafts (SVGs) and internal thoracic artery (ITA) grafts. ${ }^{2,3}$ The type of bypass graft is crucial for clinical outcome because veins and arteries have a completely different behavior with regard to early adaptation to the requirements of the myocardium and long-term patency. ${ }^{4}$

Arterial revascularization with the ITA as the bypass graft has shown excellent longterm results, ${ }^{5}$ despite the fact that early hypoperfusion can occur and can cause ischemia and contractile dysfunction. ${ }^{6,7}$ SVGs demonstrated favorable early results, although patency rates are typically lower in venous than in arterial grafts. Degenerative changes and abnormal vessel wall remodeling are enhanced in vein grafts, as well as increased platelet-vessel wall interactions, and can lead to early bypass failure. ${ }^{2,8-10}$

The purpose of this study was to assess early vascular adaptation of arterial and venous bypass grafts and to determine vascular remodeling of these grafts during the first year of follow-up. 


$$
\begin{aligned}
& \text { Abbreviations and Acronyms } \\
& \begin{aligned}
\text { CABG } & =\text { coronary artery bypass grafting } \\
\text { CFR } & =\text { coronary flow reserve } \\
\text { EDHF } & =\text { endothelium-derived hyperpolarizing factor } \\
\text { ITA } & =\text { internal thoracic artery } \\
\text { LAD } & =\text { left anterior descending coronary artery } \\
\text { LV } & =\text { left ventricular } \\
\text { NO } & =\text { nitric oxide } \\
\text { SVG } & =\text { saphenous vein graft }
\end{aligned}
\end{aligned}
$$

\section{Materials and Methods}

Thirty patients undergoing elective bypass grafting were included in the present cohort study (Figure 1). Seventeen patients had intraoperative measurements and were catheterized early (3 months, $\mathrm{n}=8)$ or late (10 months, $\mathrm{n}=9)$ after surgical intervention for follow-up measurements (group A). Furthermore, 13 matched patients with additional intraoperative hyperemic flow measurements of the ITA for calculation of coronary flow reserve (CFR) but without follow-up measurements were included (group B). The study protocol was approved by the local ethics committee, and all patients provided written informed consent. Patient characteristics are summarized in Table 1 . The mean age was $63 \pm 9$ years, $10 \%$ were women, and $90 \%$ were men. Body mass index was $29 \pm 5 \mathrm{~kg} / \mathrm{m}^{2}$. The mean left ventricular (LV) ejection fraction was $63 \% \pm 9 \%$. Twenty-five patients had multiple-vessel disease, and 5 patients had single-vessel disease. Thirteen patients had previous myocardial infarctions. Medication after bypass surgery consisted of aspirin in $94 \%, \beta$-blockers in $82 \%$, and inhibitors of the renin angiotensin system in $53 \%$. Only $6 \%$ received calcium antagonists postoperatively. Cardiovascular risk factors included a history of hypertension in $63 \%$, dyslipidemia in $67 \%$, and a family history of coronary artery disease in $37 \%$. Obesity and diabetes mellitus were present in $26 \%$ and $17 \%$ of cases, respectively. Hemodynamic and angiographic data are summarized in Table 2. LV ejection fraction was determined by means of LV angiography. Coronary artery diameter was determined by using quantitative coronary angiography with preoperative biplane coronary angiograms. Stenosis diameter was assessed for the ITA graft and SVG target vessels by using the Philips Integra System.

\section{Bypass Surgery}

General anesthesia was performed with fentanyl, midazolam, and isoflurane. Cardiopulmonary bypass with mild-to-moderate hypothermia was used. Mean cardiopulmonary bypass time was $58 \pm 25$ minutes, and aortic crossclamp time was $36 \pm 15$ minutes.

Twenty-six patients received an ITA graft to the left anterior descending coronary artery (LAD), and all patients received 1 or 2 SVGs to the diagonal and marginal branches or to the right coronary artery. Overall, 76 grafts were implanted, namely 26 ITA grafts and 50 SVGs. The mean number of distal anastomosis was $2.53 \pm 1.23$. All ITA grafts were carefully harvested as a pedicled graft. ${ }^{11}$

\section{Determination of Perfusion Territory}

The perfusion territory was determined from preoperative coronary angiograms. The method has been validated by Seiler and colleagues. ${ }^{12}$

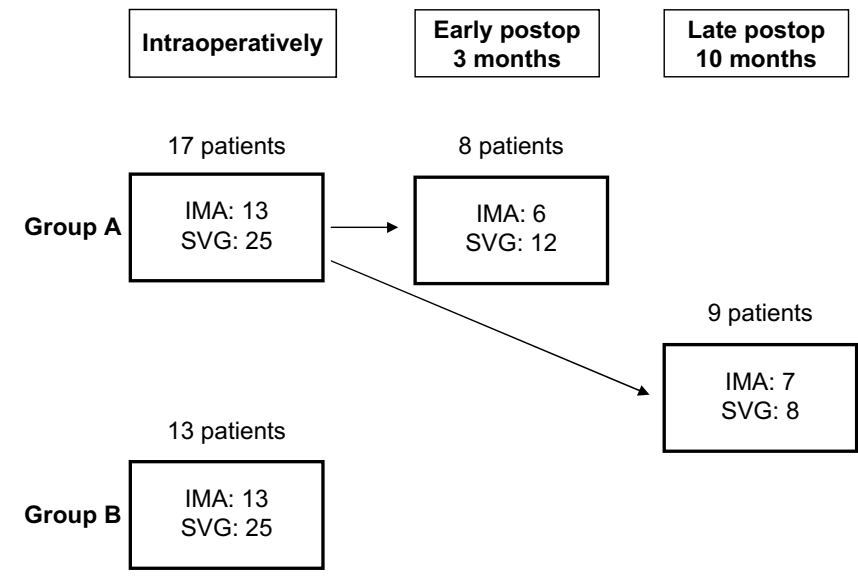

Figure 1. Study protocol. The total number of patients is 30 . Group A contains 17 patients. Eight patients of group $A$ have been studied after 3 months and 9 patients after 10 months of follow-up. Group B contains 13 patients studied intraoperatively. ITA, Internal thoracic artery; $S V G$, saphenous vein graft.

The perfusion territory was calculated from the fractional length of the coronary segments distal to the culprit lesion in relation to the total LV coronary length. This ratio was multiplied by LV muscle mass.

\section{Intraoperative Flow Measurements}

Doppler flow measurements of ITA grafts and SVGs were obtained 5 to 10 minutes after cessation of cardiopulmonary bypass, and no

\section{TABLE 1. Preoperative patient characteristics}

\begin{tabular}{lc} 
& All patients $(\mathbf{n}=\mathbf{3 0})$ \\
\hline Male/female sex $(\mathrm{n})$ & $27 / 3$ \\
Age $(\mathrm{y})$ & $63 \pm 9$ \\
Body mass index $\left(\mathrm{kg} / \mathrm{m}^{2}\right)$ & $29 \pm 5$ \\
LV ejection fraction $(\%)$ & $63 \pm 9$ \\
Perfusion territory $(\mathrm{g})$ & \\
ITA region & $75 \pm 32$ \\
SVG region & $71 \pm 27$ \\
Cardiovascular risk factors & \\
History of hypertension & $63 \%$ \\
Dyslipidemia & $67 \%$ \\
Family history of CAD & $37 \%$ \\
Smoking & $67 \%$ \\
Obesity & $26 \%$ \\
Diabetes mellitus & $17 \%$ \\
Medication (postoperatively) & \\
Aspirin & $94 \%$ \\
$\beta$-Blockers & $82 \%$ \\
ACl/ARB & $53 \%$ \\
Calcium antagonists & $6 \%$ \\
\hline
\end{tabular}

ITA, Internal thoracic artery; SVG, saphenous vein graft; $C A D$, coronary artery disease; $A C l$, angiotensin-converting enzyme inhibitors; $A R B$, angiotensin II receptor blockers. 
TABLE 2. Hemodynamic and angiographic data

\begin{tabular}{|c|c|c|c|c|c|c|c|}
\hline & Intraoperative & $P$ value & $3 \mathrm{mo}$ & $P$ value & $10 \mathrm{mo}$ & $\begin{array}{c}10 \mathrm{~m} \text { vs } \\
\text { intraoperative }\end{array}$ & $\begin{array}{c}P \text { value, } \\
\text { multiple test }\end{array}$ \\
\hline \multicolumn{8}{|l|}{ ITA } \\
\hline HR (beats/min) & $86 \pm 11$ & $<.05$ & $76 \pm 12$ & NS & $73 \pm 12$ & NS & NS \\
\hline MAP (mm Hg) & $77 \pm 9$ & $<.01$ & $109 \pm 12$ & NS & $100 \pm 13$ & $<.01$ & $<.05$ \\
\hline $\mathrm{RPP}$ (beats/min $\times \mathrm{mm} \mathrm{Hg}$ ) & $6554 \pm 985$ & $<.03$ & $8133 \pm 1293$ & NS & $7456 \pm 1384$ & NS & NS \\
\hline $\operatorname{LVEF}(\%)$ & $64 \pm 11^{*}$ & NS & $66 \pm 10$ & NS & $57 \pm 22$ & NS & NS \\
\hline LAD stenosis $(\%)$ & $78 \pm 16^{*}$ & NS & $78 \pm 18$ & NS & $85 \pm 13$ & NS & NS \\
\hline ITA diameter (mm) & - & - & $2.43 \pm 0.54$ & NS & $2.77 \pm 0.70$ & - & - \\
\hline \multicolumn{8}{|l|}{ SVG } \\
\hline HR (beats/min) & $83 \pm 9$ & $<.05$ & $73 \pm 13$ & NS & $66 \pm 9$ & $<.01$ & $<.05$ \\
\hline $\mathrm{MAP}(\mathrm{mm} \mathrm{Hg})$ & $84 \pm 12$ & $<.01$ & $104 \pm 11$ & NS & $108 \pm 12$ & $<.01$ & $<.05$ \\
\hline $\mathrm{RPP}$ (beats/min $\times \mathrm{mm} \mathrm{Hg}$ ) & $6887 \pm 936$ & NS & $7640 \pm 1771$ & NS & $7522 \pm 717$ & NS & NS \\
\hline LVEF (\%) & $62 \pm 13^{*}$ & NS & $59 \pm 15$ & NS & $64 \pm 4$ & NS & NS \\
\hline BV stenosis $(\%)$ & $85 \pm 15^{*}$ & NS & $84 \pm 17$ & NS & $90 \pm 13$ & NS & NS \\
\hline SVG diameter (mm) & - & - & $2.85 \pm 0.37$ & NS & $2.66 \pm 0.76$ & - & - \\
\hline
\end{tabular}

Values are presented as means \pm 1 standard deviation. ITA, Internal thoracic artery; $H R$, heart rate; $N S$, not significant; $M A P$, mean aortic pressure; $R P P$, ratepressure product; $L V E F$, left ventricular ejection fraction; $L A D$, left anterior descending coronary artery; $S V G$, saphenous vein graft; $B V$, bypassed target vessel. *Preoperative measurement.

vasoactive drugs were administered. Transit-time Doppler flow results were measured with the CardioMed Flowmeter (Medistim). ${ }^{11,13,14}$ The size of the flow probe was either 3,4 , or $5 \mathrm{~mm}$ depending on graft diameter. Phasic and mean flow were determined at rest in 26 ITA grafts and 20 SVGs. Hyperemic maximal flow was induced with adenosine in only 13 ITA grafts but in all SVGs (Table 3). Adenosine was infused into the left ventricle through a transmural needle at a concentration of $24 \mu \mathrm{g} \cdot \mathrm{kg}^{-1}$. $\min ^{-1}$. Simultaneously, a standard lead of the echocardiogram and systolic, diastolic, and mean arterial pressures were recorded. Vascular resistance was calculated from mean arterial pressure divided by mean bypass flow. CFR was calculated for all grafts by dividing maximal flow during adenosine infusion by baseline flow. ${ }^{15-17}$

\section{Follow-up}

All patients were followed clinically. Eight patients were restudied at 3 months and 9 patients were restudied at 10 months after surgical intervention. During restudy, baseline and hyperemic flows were determined in all ITA grafts and SVGs. Overall, 13 ITA grafts and 20 SVGs were studied postoperatively (Figure 1). Five SVGs were occluded at 3 or 10 months postoperatively and therefore not included. At follow-up, the patency rate was $100 \%$ for the ITA grafts and $80 \%$ for the SVGs, respectively.

Flow velocity was determined by using the Doppler flow wire (Cardiometrics Flo Wire, 0.014 inch) after having reached a stable position. Measurements were made in every graft at rest and during vasodilation with adenosine (adenosine bolus infusion, $18 \mu \mathrm{g}$ for the left coronary system and $14 \mu \mathrm{g}$ for the right). CABG diameter was

TABLE 3. Bypass flow, coronary flow reserve and coronary resistance

\begin{tabular}{|c|c|c|c|c|c|c|c|}
\hline & Intraoperative & $P$ value & $3 \mathrm{mo}$ & $P$ value & $10 \mathrm{mo}$ & $\begin{array}{c}10 \text { mo vs } \\
\text { intraoperative }\end{array}$ & $\begin{array}{c}P \text { value, } \\
\text { multiple test }\end{array}$ \\
\hline \multicolumn{8}{|l|}{ ITA } \\
\hline base $(\mathrm{mL} / \mathrm{min})$ & $31 \pm 8$ & NS & $42 \pm 24$ & NS & $56 \pm 30$ & $<.01$ & $<.05$ \\
\hline 0 hyper (mL/min) & $41 \pm 15$ & $<.02$ & $91 \pm 58$ & NS & $149 \pm 70$ & $<.01$ & $<.05$ \\
\hline CFR & $1.3 \pm 0.3$ & $<.01$ & $2.2 \pm 0.3$ & NS & $2.8 \pm 0.6$ & $<.01$ & $<.05$ \\
\hline CR base $\left(\mathrm{mm} \mathrm{Hg} \cdot \mathrm{mL}^{-1} \cdot \min ^{-1}\right)$ & $2.5 \pm 0.6$ & NS & $3.8 \pm 2.0$ & NS & $2.3 \pm 1.7$ & NS & NS \\
\hline CR hyper $\left(\mathrm{mm} \mathrm{Hg} \cdot \mathrm{mL}^{-1} \cdot \min ^{-1}\right)$ & $1.9 \pm 0.8$ & NS & $1.8 \pm 1.1$ & NS & $0.9 \pm 0.6$ & $<.01$ & $<.05$ \\
\hline \multicolumn{8}{|l|}{ SVG } \\
\hline 0 base $(\mathrm{mL} / \mathrm{min})$ & $58 \pm 29$ & NS & $50 \pm 27$ & NS & $46 \pm 27$ & NS & NS \\
\hline 0 hyper (mL/min) & $89 \pm 49$ & NS & $125 \pm 82$ & NS & $122 \pm 81$ & NS & NS \\
\hline CFR & $1.6 \pm 0.5$ & $<.01$ & $2.4 \pm 0.3$ & NS & $2.6 \pm 0.5$ & $<.01$ & $<.05$ \\
\hline $\mathrm{CR}$ base $\left(\mathrm{mm} \mathrm{Hg} \cdot \mathrm{mL}^{-1} \cdot \min ^{-1}\right)$ & $2.0 \pm 1.5$ & NS & $2.6 \pm 1.1$ & NS & $3.3 \pm 2.1$ & .053 & NS \\
\hline CR hyper $\left(\mathrm{mm} \mathrm{Hg} \cdot \mathrm{mL}^{-1} \cdot \min ^{-1}\right)$ & $1.4 \pm 1.1$ & NS & $1.1 \pm 0.4$ & NS & $1.4 \pm 0.9$ & NS & NS \\
\hline
\end{tabular}

Values are presented as means \pm 1 standard deviation. ITA, Internal thoracic artery; $Q$, flow; base, baseline; NS, not significant; hyper, hyperemic (adenosine); $C F R$, coronary flow reserve; $C R$, coronary resistance. 

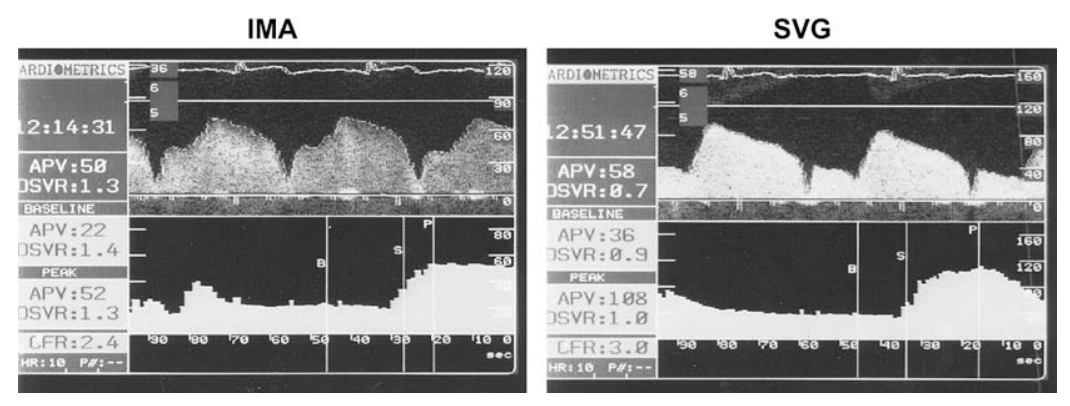

Figure 2. Original recording of flow velocity measurements of the internal thoracic artery (ITA) graft (left) and the saphenous vein graft (SVG; right) 3 months postoperatively. The flow velocity curve during maximal vasodilation with adenosine (top) and trend analysis (bottom) is shown. Coronary flow reserve is $\mathbf{2 . 4}$ for the ITA graft and 3.0 for the SVG.

measured at the tip of the flow wire for normalization of flow velocity to flow. Absolute flow was calculated by using the following formula: $F=A \cdot v$, where $F$ is defined as flow, $A$ is defined as the cross-sectional area of the vessel, and $v$ is defined as flow velocity. ${ }^{18}$ Average flow was calculated from 3 separate flow measurements. Graft diameters of the ITA grafts and SVGs were measured quantitatively at 3 and 10 months postoperatively.

\section{Statistics}

Data are expressed as means \pm 1 standard deviation in all tables and as means \pm 1 standard error of the mean in all figures. The Wilcoxon signed-ranks test was used to compare nonparametric paired observations, and the Mann-Whitney $U$ test was used to compare nonparametric unpaired observations, such as comparisons between ITA graft and SVG data, as well as between baseline and hyperemic flows. Because multiple measurements of graft flow were made, the Kruskal-Wallis nonparametric test for comparison of different groups was used to compare the postoperative flow data of the ITA grafts and SVGs. Noncontinuous descriptive parameters were compared by using the $\chi^{2}$ test.

\section{Results}

A representative flow velocity tracing is shown in Figure 2 in a patient 3 months postoperatively. Flow velocity curves during hyperemia and trend analysis are shown for the ITA graft and the SVG. CFR is 2.4 for the ITA graft and 3.0 for the SVG.

\section{Hemodynamic and Angiographic Data}

The perfusion territory was slightly larger in the ITA graft than in the SVG region $(75 \pm 32$ vs $71 \pm 27 \mathrm{~g}$, Table 1$)$. Heart rate was significantly higher intraoperatively than during follow-up (Table 2). Conversely, mean arterial pressure was significantly lower intraoperatively than during follow-up. As a consequence, rate-pressure product was lower intraoperatively than during early follow-up but not during late follow-up. LV ejection fraction was similar preoperatively and postoperatively. Angiographic stenosis of the vessel bypassed by the ITA (LAD stenosis) was $78 \% \pm$ $16 \%$ and by the SVG was $85 \% \pm 15 \%$ preoperatively and did not change significantly during follow-up. ITA graft diameter tended to increase slightly from 3 to 10 months postoperatively, whereas SVG diameter even decreased slightly.

\section{Bypass Flow, CFR, and Resistance}

Resting bypass flow was significantly lower in the ITA graft than in the SVG but increased during late follow-up significantly in the ITA graft and decreased or remained unchanged in the SVG (Table 3 and Figures 3 and 4). Maximal bypass flow during adenosine infusion was intraoperatively significantly lower in the ITA graft than in the SVG (Table 3) and increased linearly and significantly after surgical intervention in the ITA group (Figures 3 and 4), whereas there was a step up of $40 \%$ in the SVGs early after CABG, which remained unchanged during late follow-up.

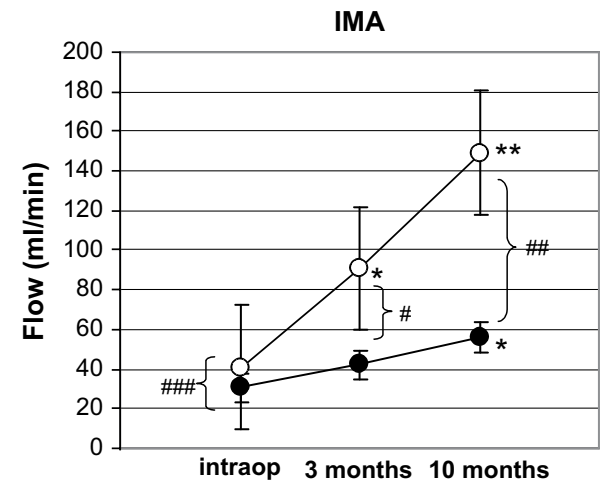

$\# \mathrm{p}<0.05$

\#\# $\mathrm{p}<0.025$

\#\#\# $\mathrm{p}<0.01$

$* \mathrm{p}<0.025$ vs intraop

$* * \mathrm{p}<0.01$ vs intraop
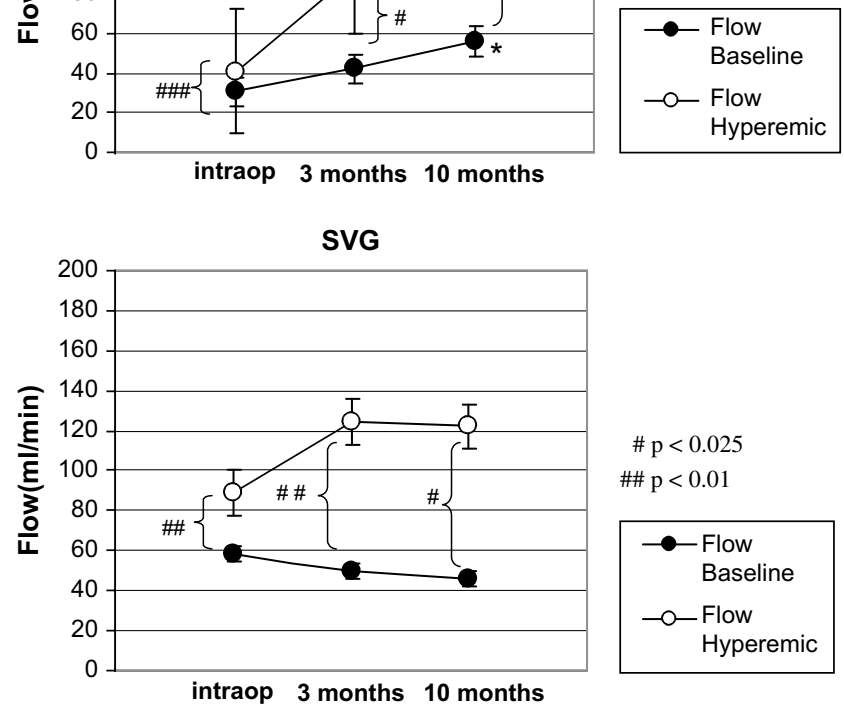

$\# \mathrm{p}<0.025$

$\#$ \# $<0.01$

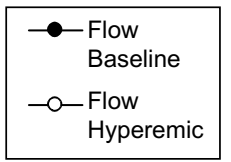

Figure 3. Bypass flow. Baseline values compared with hyperemic flow are shown intraoperatively and 3 months and 10 months after surgical intervention for the internal thoracic artery (ITA) graft (top) and the saphenous vein graft (SVG; bottom). 

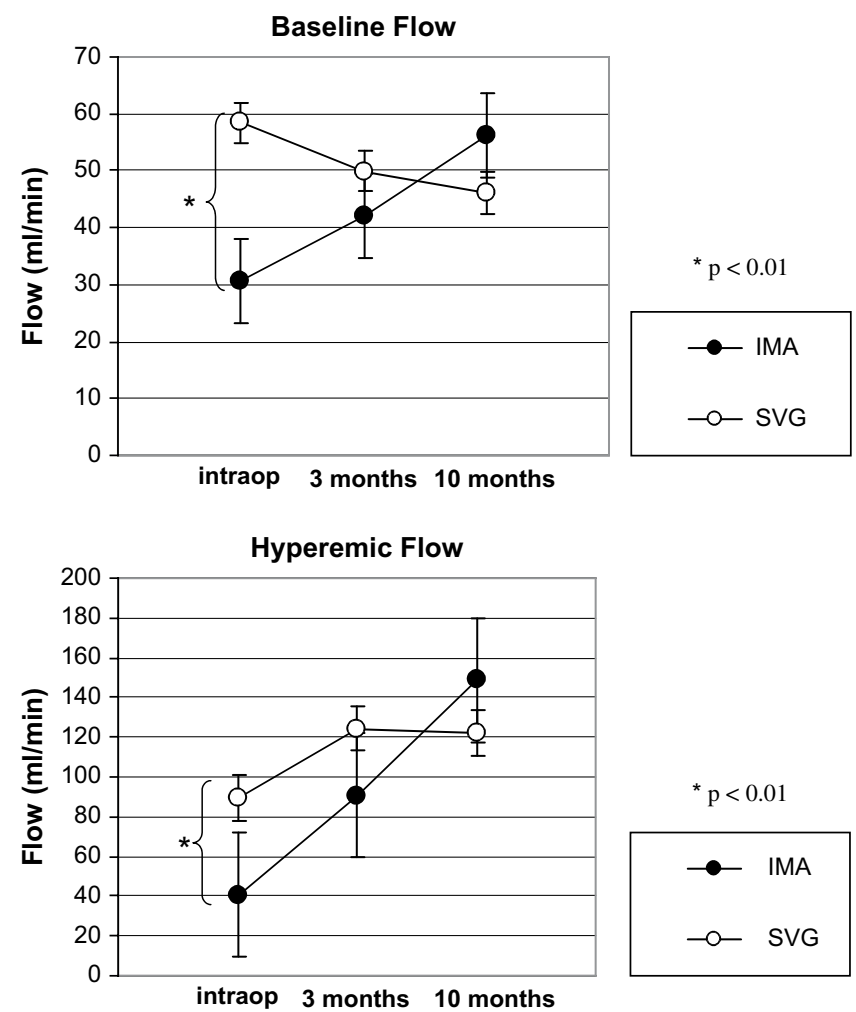

Figure 4. Baseline and hyperemic flow (internal thoracic artery [ITA] graft vs saphenous vein graft [SVG]. Baseline flow (top) and hyperemic flows (bottom) for the ITA graft compared with the SVG are shown intraoperatively and 3 and 10 months postoperatively. Baseline and hyperemic flows are significantly reduced for the ITA graft compared with the SVG intraoperatively $(P<.01)$.

There was an increase in ITA baseline flow in 5 of 6 patients at 3 months and 5 of 7 patients at 10 months postoperatively, whereas SVG baseline flow values increased only in 5 of 12 patients at 3 months and 1 of 8 patients at 10 months postoperatively $(P<.05)$.

CFR increased continuously in both ITA grafts and SVGs (Table 3 and Figure 5). There was a significant increase in CFR during early follow-up in both groups, and this increase remained significant during late follow-up.

Coronary resistances at baseline and during hyperemia showed a similar pattern in both ITA grafts and SVGs, although there was a trend toward lower resistances in the vein grafts (Table 3 ).

There were no differences in flow measurements in patients with and without diabetes mellitus.

\section{Differences Between ITA Graft and SVG Bypass Flow}

Generally, the ITA grafts tended to have smaller flows at rest and during hyperemia intraoperatively. During postoperative follow-up, ITA graft flow increased both at baseline and during hyperemia, whereas SVG flow at baseline decreased but

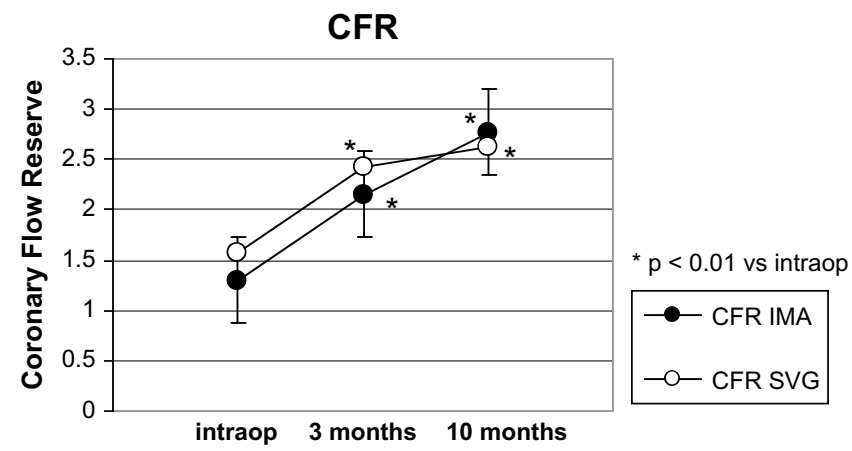

Figure 5. Coronary flow reserve (CFR) for the internal thoracic artery (ITA) graft compared with the saphenous vein graft (SVG) is shown intraoperatively and 3 and 10 months postoperatively. There is no difference between the ITA graft and the SVG. CFR is significantly increased for both the ITA graft and the SVG 3 and 10 months after the operation $(P<.01)$.

increased during maximal vasodilation early, but not late, after revascularization. There was an $81 \%$ increase in baseline flow and a $263 \%$ increase in maximal flow of the ITA graft. In contrast, there was a decrease of $21 \%$ in baseline flow and an increase of $37 \%$ in maximal flow of the SVG.

Parallel to the flow changes, graft diameter increased or decreased (Table 2 and Figure 6). The flow increase in the ITA grafts was associated with a $16 \%$ increase in graft diameter, whereas the diameter decreased by $7 \%$ in the SVGs. For both grafts, there was a significant correlation between flow and diameter (Figure 6).

\section{Discussion}

Vascular remodeling has been described for the ITA after use as a bypass vessel for the coronary arteries. ${ }^{19-21}$ Early flow mismatch after bypass surgery has been reported for the ITA, mainly because of the fact that this small artery often shows vasospasms with hypoperfusion of the grafted artery. ${ }^{6,22,23}$ However, most patients show excellent longterm results after revascularization with vascular adaptation of the ITA. ${ }^{2}$

The purpose of the present study was to assess vascular adaptation of the ITA graft and SVG early and late after bypass surgery. The following observations were made:

1. Bypass flow of the ITA graft is significantly reduced intraoperatively when compared with that of the SVG.

2. Vascular adaptation of the ITA graft with an increase in resting bypass flow is observed with a $35 \%$ increase at 3 months and an $81 \%$ increase at 10 months. Parallel to the flow increase, the ITA graft diameter tends to increase slightly from 3 to 10 months. Bypass flow at 10 months is $22 \%$ higher in the ITA graft compared with that in the SVG. 

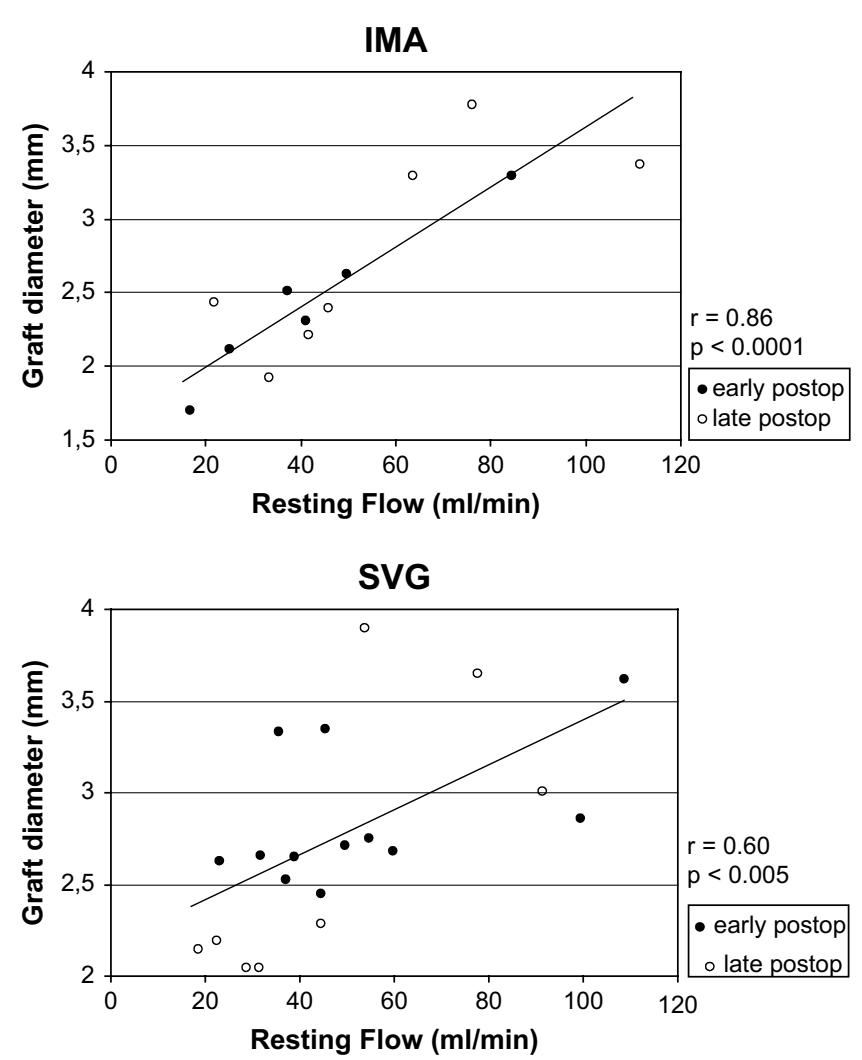

Figure 6. Correlation between resting graft flow and graft diameter early (3 months) and late (10 months) postoperatively. The internal thoracic artery (ITA) graft diameter increased by $16 \%$, and the saphenous vein graft (SVG) diameter decreased by $7 \%$. There is a significant correlation both for the ITA graft and the SVG, with a better Pearson's regression for the ITA graft $(r=0.86)$ than for the SVG $(r=0.60)$.

3. Vascular adaptation of the ITA graft shows approximately a doubling of baseline flow and a quadrupling of hyperemic flow, probably because of endotheliummediated mechanisms.

\section{Pathophysiologic Mechanisms}

Flow mismatch in the perioperative setting can be the result of poor surgical technique with anastomosis failure. ${ }^{24,25}$ However, vasospasms of the arterial graft, competitive flow through the native coronary artery, or undersized bypass vessels for a given myocardial perfusion territory might be other reasons for flow-perfusion mismatch. ${ }^{23,26}$ Vasospasms have been associated with harvesting of the ITA graft, increased neurohormonal stress, and cardiac surgery trauma.

In the present analysis ITA graft flow was intraoperatively approximately 50\% lower than SVG flow (Table 3). In other words, the ITA-perfused myocardial region receives only half of the flow received by the SVG-perfused region. This low-perfusion situation might cause problems in patients with high vascular resistance, increased catecholamine drive, and vasospasms of the ITA bypass graft. Therefore the use of SVG has potential benefits in acute situations with low pressure and high catecholamine levels. ${ }^{6,7,22}$

Early after the operation (3 months), there is an adaptation of the ITA graft with an increase in baseline and maximal flow, but it is still $16 \%$ lower at baseline and $27 \%$ at maximal flow than SVG flow. These early changes in bypass flow of the ITA graft could be explained by flow-mediated mechanisms ${ }^{21,27}$ or by decreased neurohormonal stress and recovery from cardiac surgery trauma. ${ }^{28}$ The endothelium is able to respond to flow changes and produces 3 known relaxing factors: nitric oxide (NO), prostacyclin, and endothelium-derived hyperpolarizing factor (EDHF). ${ }^{29-32}$ Several reports in the literature have shown that the ITA graft is able to produce more prostacyclin, ${ }^{33} \mathrm{NO}$, and $\mathrm{EDHF}^{34}$ than the SVG. These findings could partially explain the superior long-term patency of ITA grafts. Additionally, the endothelium-derived factors could be responsible for the adaptation of ITA grafts to the altered hemodynamic situation after anastomosis to the coronary bed. Bellien and associates ${ }^{35}$ showed that $\mathrm{NO}$ and EDHF are involved in flow-mediated dilatation of conduit arteries. Popp and colleagues ${ }^{36}$ demonstrated that the synthesis of EDHF can be mechanically stimulated in coronary arteries by means of rhythmic vessel wall distension, and this suggests that EDHF might contribute to the control of coronary blood flow. All these findings suggest that analogous mechanisms could occur in ITAs after bypass surgery and be responsible for the adaptation of the grafts to coronary blood flow, resulting in a positive vascular remodeling with a possible increase in graft diameter.

Vascular adaptation is, however, not complete after 3 months because adaptation continues until 10 months after the operation. At this time point, baseline flow of the ITA graft is $20 \%$, and maximal flow is $22 \%$ higher than SVG flow, which was more or less unchanged between 3 and 10 months. The slightly higher maximal flow of the ITA graft might be explained in part by the larger myocardial perfusion territory. The perfusion territory, as assessed by means of quantitative coronary angiography (Table 1), was slightly larger for the ITA $(75 \mathrm{~g})$ than the SVG $(71 \mathrm{~g})$ perfusion region.

Interestingly, CFR is similar in both ITA grafts and SVGs (Figure 5), increasing in both grafts from approximately 1.5 intraoperatively to 2.7 at 10 months postoperatively (both $P<.01$ ). After 10 months, CFR amounts to 2.8 in the ITA graft and 2.6 in the SVG, which indicates normal flow reserve at this time after the operation. A normal flow reserve is considered to be greater than $2.5 .{ }^{17}$ Thus intraoperatively and early postoperatively, CFR is reduced, indicating a reduction in myocardial perfusion during high-flow situations. Thus adaptation of the bypass to the new hemodynamic situation requires more than 3 but less than 10 months. The changes in CFR are similar for the ITA graft and the SVG, although 
the changes in baseline and hyperemic flows are almost opposite. This suggests that the requirements of the perfused tissues are closely regulated through CFR and not through the maximal coronary blood flow. ${ }^{37}$ Similar observations have previously been made after coronary stenting, when CFR increased after percutaneous transluminal coronary angioplasty from 2.5 to 3.1 at 6 months' follow-up. ${ }^{38}$

From a theoretic standpoint, it might be possible that coronary resistance is different in LAD territories than in nonLAD territories, and thus flow is less in ITA grafts than in SVGs. However, previous data from Flemma and coworkers ${ }^{6}$ suggest that this is probably not the case because they showed a 2 to 3 times higher flow in the SVG than in the ITA graft when both were anastomosed to the LAD.

Patients with previous myocardial infarctions had slightly lower LV ejection fractions (56\% vs 63\%) than those without. Coronary flow in these regions was, however, similar intraoperatively ( $33 \mathrm{vs} 27 \mathrm{~mL} / \mathrm{min}$ for ITA grafts and 52 vs $58 \mathrm{~mL} / \mathrm{min}$ for SVGs), suggesting no direct effect of myocardial viability on coronary flow in this setting.

\section{Study Limitations}

Intraoperative flow measurements are dependent on the measuring site and the fit of the flow probe on the examined vessel (coupling factor). However, optimal coupling between the flow probe and the bypass graft was achieved by selecting the appropriate probe size (ie, a 3- to 4-mm flow probe for the ITA graft and a 4- to 5-mm probe for the SVG).

Intraoperative and postoperative hemodynamics are clearly different. During the operation, heart rate is higher and blood pressure lower, and as a consequence, the ratepressure product is reduced. Thus oxygen requirements of the myocardium are reduced, and bypass flow is less than under stable conditions. ${ }^{39}$

The method of blood flow measurement differs intraoperatively and postoperatively. This could be a source of a certain methodological bias. There are several studies comparing electromagnetic flow measurements with Doppler Flow wire data. ${ }^{18,40}$ Electromagnetic flow probes have been compared with transit-time Doppler probes, with excellent correlations between the 2 techniques. ${ }^{14}$ Both methods have been validated as reliable tools for flow and flow-velocity measurements, respectively. ${ }^{14,18}$ Thus although both methods differ, the results are comparable and are based on the same technique.

The number of patients is rather small, but this kind of examination is demanding, and patients have to undergo a second round of elective coronary angiography with its unpleasant side effects. Therefore patients are different between the early and late postoperative examinations.

\section{Clinical Implications}

Early postoperative hypoperfusion of up to $50 \%$ is possible with ITA grafts. This phenomenon is due to the undersized native ITA vessel, which is connected to a high-flow perfusion bed.
In contrast, the SVG permits maximal perfusion immediately after implantation and thus provides hemodynamic advantages in acute situations with low pressure and high catecholamine drive ${ }^{6,7,22}$ However, in the ITA graft vascular adaptation occurs early after the operation, with a flow doubling at 10 months. There is a linear increase after the operation in baseline and maximal bypass flows of the ITA, with a possible increase in graft diameter (Figures 4 and 6), whereas the SVG shows a decrease in baseline flow and a step up (40\%) of maximal flow in the early postoperative phase that remains unchanged at 10 months' follow-up. This finding is paralleled by an unchanged or even slightly decreased SVG diameter. In a subgroup analysis of diabetic patients, no differences in vascular resistance or CFR were found.

Thus vascular adaptation of the ITA graft is an important mechanism of this type of artery, which allows flow normalization over time with optimal perfusion of the bypassed artery. However, there is a time delay in the adaptation that lasts up to 10 months. This finding suggests a positive vascular remodeling of the artery.

From a practical standpoint, hypoperfusion of the LAD territory by an undersized ITA graft has to be taken into consideration and might improve over time. Postoperative application of intravenous nitrates (cave low perfusion pressure) or calcium antagonists might improve the limited ITA graft flow situation. Some surgeons recommend the general use of calcium antagonists for up to 3 months after ITA bypass surgery to compensate for a potential hypoperfusion of the ITA-grafted territory.

We thank the personnel of the operating room and the catheterization laboratories for their help during the study.

\section{References}

1. Lytle BW, Cosgrove DM 3rd. Coronary artery bypass surgery. Curr Probl Surg. 1992;29:733-807.

2. Lytle BW, Loop FD, Cosgrowe DM, Ratliff NB, Easley K, Taylor PC. Long-term (5 to 12 years) serial studies of internal mammary artery and saphenous vein coronary bypass grafts. $J$ Thorac Cardiovasc Surg. 1985;89:248-58.

3. Gillinov AM, Loop FD. Long-term results of internal thoracic artery grafting. In: He GW, ed. Arterial grafts for coronary artery bypass surgery. Singapore: Springer-Verlag; 1999.p.61-176.

4. Bach RG, Kern MJ, Donohue TJ, Aguirre FV, Caracciolo EA. Comparison of phasic blood flow velocity characteristics of arterial and venous coronary artery bypass conduits. Circulation. 1993;88(suppl II):133-40.

5. Loop FD, Lytle BW, Cosgrove DM. Influence of internal mammary artery graft on 10-year survival and other cardiac events. $N$ Engl $J$ Med. 1986;314:1-6.

6. Flemma RJ, Singh HM, Tector AJ, Lepley D, Frazier BL. Comparative hemodynamic properties of vein and mammary artery in coronary bypass operations. Ann Thorac Surg. 1975;20:619-27.

7. v Segesser L, Simonet F, Meier B, Finci L, Faidutti B. Inadequate flow after internal mammary-coronary artery anastomoses. Thorac Cardiovasc Surg. 1987;35:352-4.

8. Mekontso-Dessap A, Kirsch M, Guignambert C, Zadigue P, Adnot S, Loisance D, et al. Vascular-wall remodeling of 3 human bypass vessels: organ culture and smooth muscle cell properties. $J$ Thorac Cardiovasc Surg. 2006;131:651-8. 
9. Yang Z, Stulz P, von Segesser L, Bauer E, Turina M, Lüscher TF. Different interactions of platelets with arterial and venous coronary bypass vessels. Lancet. 1991;337:939-43.

10. Yang Z, Oemar B, Carrel T, Kipfer B, Julmy F, Lüscher TF. Different proliferative properties of smooth muscle cells of human arterial and venous bypass vessels: role of PDGF receptors, mitogen-activated protein kinase, and cyclin-dependent kinase inhibitors. Circulation. 1998;97: 181-7.

11. Walpoth BH, Mohadjer A, Gersbach P, Rogulenko R, Walpoth BN, Althaus U. Intraoperative internal mammary artery transit-time flow measurements: comparative evaluation of two surgical pedicle preparation techniques. Eur J Cardiothorac Surg. 1996;10:1064-70.

12. Seiler C, Kirkeeide RL, Gould KL. Measurement from arteriograms of regional myocardial bed size distal to any point in the coronary vascular tree for assessing anatomic area at risk. J Am Coll Cardiol. 1993;21: 783-97.

13. Canver CHC, Dame NA. Ultrasonic assessment of internal thoracic artery graft flow in the revascularized heart. Ann Thorac Surg. 1990; 58:135-8.

14. Beldi G, Bosshard A, Hess OM, Althaus U, Walpoth BH. Transit time flow measurement: experimental validation and comparison of three different systems. Ann Thorac Surg. 2000;70:212-7.

15. Klocke FJ. Quantitative evaluation of coronary perfusion in man. Cathet Cardiovasc Diagn. 1975;1:349-60.

16. Klocke FJ. Measurements of coronary flow reserve: defining pathophysiology versus making decisions about patient care. Circulation. 1987;76: 1183-9.

17. Vassalli G, Hess OM. Measurement of coronary flow reserve and its role in patient care. Basic Res Cardiol. 1998;93:339-53.

18. Doucette JW, Corl PD, Payne HM, Flynn AE, Goto M, Nassi M, et al. Validation of a Doppler guide wire for intravascular measurement of coronary artery flow velocity. Circulation. 1992;85:1899-911.

19. De Bono DP, Samani NJ, Spyt TJ, Hartshorne T, Thrush A, Evans DH. Transcutaneous ultrasound measurement of blood-flow in internal mammary artery to coronary artery grafts. Lancet. 1992;339:379-81.

20. Gurne O, Chenu P, Polidori C, Louagie Y, Buche M, Haxhe JP, et al. Functional evaluation of internal mammary artery bypass grafts in the early and late postoperative periods. J Am Coll Cardiol. 1995;25: $1120-8$.

21. Barner HB. Remodeling of arterial conduits in coronary grafting. Ann Thorac Surg. 2002;73:1341-5.

22. Carrel T, Kujawski T, Zund G, Schwitter J, Amann FW, Gallino A, et al. The internal mammary artery malperfusion syndrome: incidence, treatment and angiographic verification. Eur Cardiothorac Surg. 1995;9: 190-7.

23. Barner HB. The continuing evolution of arterial conduits. Ann Thorac Surg. 1999;68(suppl 1):1-8.

24. Walpoth BH, Bosshard A, Genyk I, Kipfer B, Berdat PA, Hess OM, et al. Transit-time flow measurement for detection of early graft failure during myocardial revascularization. Ann Thorac Surg. 1998;66: 1097-100.

25. D'Ancona G, Karamanoukian HL, Ricci M, Schmid S, Bergsland J, Salerno TA. Graft revision after transit time flow measurement in off-pump coronary artery bypass grafting. Eur J Cardiothorac Surg. 2000;17:287-93.

26. Caputo M, Nicolini F, Franciosi G, Galloti R. Coronary artery spasm after coronary artery bypass grafting. Eur J Cardiothorac Surg. 1999; 15:545-8.

27. Lüscher TF, Diederich D, Siebenmann R, Lehmann K, Stulz P, v Segesser L, et al. Difference between endothelium-dependent relaxation in arterial and in venous coronary bypass grafts. $N$ Engl J Med. 1988; 319:462-7.

28. Aris A, Borràs X, Ramio J. Patency of internal mammary artery grafts in no-flow situations. J Thorac Cardiovasc Surg. 1987;93:62-4.

29. Ignarro LJ, Buga GM, Wood RS, Byrns RE, Chaudhuri G. Endothelialderived relaxing factor produced and released from artery and vein is nitric oxide. Proc Natl Acad Sci U S A. 1987;84:9265-9.

30. Cohen RA, Vanhoutte PM. Endothelium-dependent hyperpolarization: beyond nitric oxide and cyclic GMP. Circulation. 1995;92:3337-49.

31. Pearson PJ, Evora PR, Schaff HV. Bioassay of EDRF from internal mammary arteries: implications for early and late bypass graft patency. Ann Thorac Surg. 1992;54:1078-84.

32. Chua YL, Pearson PJ, Evora PR, Chaff HV. Detection of intraluminal release of endothelium-derived relaxing factor from human saphenous veins. Circulation. 1993;88(suppl II):128-32.

33. Chaikhouni A, Crawford FA, Kochel PJ, Olanoff LS, Halushka PV. Human internal mammary artery produces more prostacyclin than saphenous vein. J Thorac Cardiovasc Surg. 1986;92:88-91.

34. Zhi-Gang L, Zhi-Dong G, Guo-Wei H. Difference in endotheliumderived hyperpolarizing factor-mediated hyperpolarization and nitric oxide release between human internal mammary artery and saphenous vein. Circulation. 2000;102:III-296-III-301.

35. Bellien J, Iacob M, Gutierrez L, Isabelle M, Lahary A, Thuillez C, et al. Crucial role of NO and endothelium-derived hyperpolarizing factor in human sustained conduit artery flow-mediated dilatation. Hypertension. 2006;48:1088-94.

36. Popp R, Fleming I, Busse R. Pulsatile stretch in coronary arteries elicits release of endothelium-derived hyperpolarizing factor. Circ Res. 1998; 82:696-703.

37. Gaudino M, Serricchio M, Tondi P, Glieca F, Giordano A, Trani C, et al. Non-invasive evaluation of mammary artery flow reserve and adequacy to increased myocardial oxygen demand. Eur J Cardiothorac Surg. 1998;13:404-9.

38. Haude M, Baumgart D, Verna E, Piek J, Vrints C, Probst P, et al. Intracoronary Doppler- and quantitative coronary artery-derived predictors of major adverse cardiac events after stent implantation. Circulation. 2001; 103:1212-7.

39. Bierbach B, Kasper-Konig W, Haist T, Meier M, Pritzer H, Hanenkamp U, et al. Effect of different operative techniques for myocardial revascularisation on hemodynamics and myocardial perfusion in a porcine model. Thorac Cardiovasc Surg. 2005;53:103-9.

40. Labovitz AJ, Anthonis DM, Cravens TL, Kern MJ. Validation of volumetric flow measurements by means of a Doppler-tipped coronary angioplasty guide wire. Am Heart J. 1993;126:1456-61. 